\title{
Melanoma Differentiation-Associated Gene 5 Regulates the Expression of a Chemokine CXCL10 in Human Mesangial Cells: Implications for Chronic Inflammatory Renal Diseases
}

\author{
Tadaatsu Imaizumi, ${ }^{1}$ Tomomi Aizawa-Yashiro, ${ }^{2}$ Kazushi Tsuruga, ${ }^{2}$ \\ Hiroshi Tanaka, ${ }^{2,4}$ Tomoh Matsumiya, ${ }^{1}$ Hidemi Yoshida, ${ }^{1}$ Tetsuya Tatsuta, ${ }^{3}$ \\ Fei Xing, ${ }^{1}$ Ryo Hayakari ${ }^{1}$ and Kei Satoh ${ }^{1}$ \\ ${ }^{1}$ Department of Vascular Biology, Hirosaki University Graduate School of Medicine, Hirosaki, Japan \\ ${ }^{2}$ Department of Pediatrics, Hirosaki University Graduate School of Medicine, Hirosaki, Japan \\ ${ }^{3}$ Department of Gastroenterology, Hirosaki University Graduate School of Medicine, Hirosaki, Japan \\ ${ }^{4}$ Department of School Health Science, Faculty of Education, Hirosaki University, Hirosaki, Japan
}

Mesangial cells play an important role in inflammatory reactions in kidney. Although viral infections often trigger the worsening of chronic inflammatory renal diseases, the mechanisms are largely unknown. Melanoma differentiation-associated gene 5 (MDA5) is a member of RNA helicase family with a conserved Asp-Glu-x-His (DExH) box. In the present study, we examined the effect of polyinosinic-polycytidylic acid (poly IC), an authentic double-stranded RNA (dsRNA) that mimics viral dsRNAs, on MDA5 expression using primary culture of human mesangial cells. The cells were simply treated or transfected with poly IC; the former procedure is a model of cells exposed to viral dsRNA released from dying cells, and the latter is a model of entry of RNA virus into the cytoplasm. Expression levels of MDA5 mRNA in mesangial cells were increased about 70-100 fold in response to either treatment or transfection with poly IC. MDA5 protein expression was significantly induced as well. RNA interference experiments revealed that poly IC treatment induced MDA5 expression via Toll-like receptor 3 (TLR3) and interferon (IFN)- $\beta$, and that poly IC trasnfection induced MDA5 expression via another DExH box RNA helicase, retinoic acid-inducible gene-I (RIG-I), and IFN- $\beta$. Moreover, MDA5 induced by poly IC, in turn, increased the expression of a chemokine CXCL10. In addition, immunohistochemical staining demonstrated a high level of MDA5 expression in glomeruli, mainly in mesangial cells, of patients with severe lupus nephritis or proteinuric IgA nephropathy. MDA5 may be involved not only in physiological antiviral reactions but also in chronic inflammation in glomerular mesangial cells.

Keywords: CXCL10; MDA5; mesangial cells; RIG-I; TLR3

Tohoku J. Exp. Med., 2012 Sep, 228 (1), 17-26. (C) 2012 Tohoku University Medical Press

Melanoma differentiation-associated gene 5 (MDA5) was first identified as a gene induced by interferon (IFN)- $\beta$ in melanoma cells and implicated in the IFN- $\beta$-mediated suppression of melanoma growth (Kang et al. 2002). There is an Asp-Glu- $\mathrm{x}-\mathrm{His}$ (DExH) box in amino acid alignment of MDA5 protein, and proteins with a DExH box encode RNA helicases that are involved in various biological reactions associated with RNA metabolism (Schwer 2001). Another DExH protein retinoic acid-inducible gene-I (RIGI) was identified as a lipopolysaccharide-inducible gene in endothelial cells (Imaizumi et al. 2002) and separately as a retinoic acid-inducible gene in leukemia cells (Jiang et al. 2011). Recently, it was shown that MDA5 and RIG-I function as pathogen recognition receptors against viral doublestranded RNA (dsRNA) and these two molecules may play an important role in innate immune reactions against viral infection (Yoneyama et al. 2005).

When the cells were infected with certain viruses, dsRNA is generated in association with replication of viruses. In the process of innate immune reactions, dsRNA may be recognized by pattern recognition receptors such as Toll-like receptor (TLR) 3, RIG-I and MDA5 (Yoneyama et al. 2005; Patole et al. 2005). TLR3 may sense viral dsRNA released from dying cells, and viral dsRNA in cytoplasm may be recognized by RIG-I or MDA5. Both MDA5 and RIG-I have C-terminal DExH domains and N-terminal caspase recruit domains; the former recognizes viral doublestranded RNA and the latter activates the downstream antiviral signaling pathways (Yoneyama et al. 2005).

Viral infections often cause the onset or worsening of

Received July 11, 2012; accepted August 1, 2012. Published online August 11, 2012; doi: 10.1620/tjem.228.17.

Correspondence: Tadaatsu Imaizumi, Department of Vascular Biology, Hirosaki University Graduate School of Medicine, 5 Zaifu-cho, Hirosaki 036-8562, Japan.

e-mail: timaizum@cc.hirosaki-u.ac.jp 
glomerulonephritis (Lai and Lai 2006). Glomerular mesangial cells are involved in the immune and inflammatory reactions in the kidney by producing a variety of functional molecules. Therefore, it may be important to clarify the details of anti-viral reactions in mesangial cells to understand the molecular mechaninsms of glomerulonephritis related to viral infections.

Polyinosinic-polycytidylic acid (poly IC) is an authentic dsRNA. When applied to cells, poly IC mimics viral infections and induces anti-viral immune reactions. It has been reported that treatment of mesangial cells with poly IC enhanced the expression of factors as IFN- $\beta$, interleukin-6, CCL2, CCL5, intercellular adhesion molecule-1, macrophage-colony stimulating factor, metalloproteinases, RIG-I and IFN-stimulated genes (ISGs) (Flur et al. 2009; Wörnle et al. 2009; Allam et al. 2009; Imaizumi et al. 2010, 2011).

Although MDA5 expression has been demonstrated in mouse (Flur et al. 2009) and human mesangial cells (Imaizumi et al. 2011), details about the mechanisms by which MDA5 expression is regulated have not been clarified. We herein addressed the effect of poly IC on the expression of MDA5 and the role of MDA5 in CXCL10 expression in cultured human mesangial cells. Immunofluorescent staining for MDA5 was also performed on biopsy specimens from patients with lupus nephritis or IgA nephropathy.

\section{Materials and Methods}

Reagents

Poly IC, anti-actin rabbit $\operatorname{IgG}$ and a fluorescein isothiocyanate (FITC)-conjugated anti-rabbit IgG antibody were from Sigma (St. Louis, MA, USA). An RNeasy total RNA isolation kit, small interfering RNA (siRNA) against TLR3 (SI02655156), RIG-I (SI03019646) or MDA5 (SI03649037) and non-silencing negative control siRNA (1027281) were from Qiagen (Hilden, Germany). Primer oligo $(\mathrm{dT})_{12-18}$, dNTP mix, MMLV reverse transcriptase and Lipofectamine RNAiMAX were purchased from InVitrogen (Frederick, MD, USA). SsoFast EvaGreen Supermix was from BioRad (Herculus, CA, USA). Oligonucleotide primers for polymerase chain reaction (PCR) were custom synthesized by Greiner Japan (Atsugi, Japan). An anti-MDA5 rabbit polyclonal antibody (29020) was from Immuno-Biological Laboratories (Takasaki, Japan). An antibody against TLR3 was from ENZO Life Sciences (Farmingdale, NY, USA) and a horseradish peroxidase-conjugated anti-rabbit secondary antibody was from Santa Cruz (Santa Cruz, CA, USA). A rabbit polyclonal antibody against RIG-I was raised as described previously (Imaizumi et al. 2002). A Luminata Crescendo chemiluminescence substrate and polyvinylidene difluoride membranes were from Millipore (Billeriva, MA, USA). Recombinant human (r(h)) IFN- $\beta$ was from ProSpec (Rehovot, Israel). siRNA against IFN- $\beta$ and an expression plasmid for IFN- $\beta$ in pcDNA3.1 were prepared as described previously (Imaizumi et al. 2010). A FuGENE HD transfection reagent was from Roche Diagnostics (Basel, Switzerland). An enzyme-linked immunosorbent assay (ELISA) kit for CXCL10 or IFN- $\beta$ was from R\&D systems (Minneapolis, MN, USA) or Kamakura Techno-Science (Kamakura, Japan), respectively.

Cells

Normal human mesangial cells in primary culture were purchased from Lonza (Walkersville, MD, USA) and cultured in MsGM (Lonza) according to the manufacturer's instruction. The cells cultured in 6-well plates were treated with $2-50 \mu \mathrm{g} / \mathrm{ml}$ poly IC or transfected with $0.2-5 \mathrm{ng} / \mathrm{ml}$ poly IC complexed with a cationic lipid, Lipofectamine RNAiMAX. One day before the transfection, culture medium was replaced with the medium without antibiotics. Cell density at transfection was $30-50 \%$ confluence. The cells were also transfected with 20 pmoles/well of non-silencing control siRNA or siRNA against TLR3, RIG-I, IFN- $\beta$ or MDA5 using a Lipofectamine RNAiMAX reagent. Transfection with an IFN- $\beta$ expression construct was performed using a FuGENE HD reagent according to the manufacturer's protocol. The viability of cells was more than $90 \%$ in the conditions used.

\section{$R N A$ extraction and reverse transcription (RT)-PCR analysis}

Total RNA was extracted from cells using an RNeasy RNA extraction kit. Single-strand cDNA was synthesized from $1 \mu \mathrm{g}$ of total RNA using oligo(dT) $)_{12-18}$ primer and Moloney Murine Leukemia Virus (MMLV) reverse transcriptase. Reverse transcription was performed at $37^{\circ} \mathrm{C}$ for $60 \mathrm{~min}$. The cDNA for MDA5, CXCL10, IFN- $\beta$ or glyceraldehyde-3-phosphate dehydrogenase (GAPDH) was amplified with an SsoFast EvaGreen Supermix and specific primers using CFX96 real-time PCR detection system (Bio-Rad). The primers used are shown in Table 1.

\section{Western blot analysis}

Western blot analysis was performed as described (Imaizumi et

Table 1. Oligonucleotide primers for real-time PCR.

\begin{tabular}{|c|c|c|c|c|}
\hline cDNA & primers & $\begin{array}{c}\text { annealing } \\
\left({ }^{\circ} \mathrm{C}\right)\end{array}$ & cycles & $\begin{array}{l}\text { product } \\
\text { (bp) }\end{array}$ \\
\hline MDA5 & $\begin{array}{l}\text { F: 5'-GTTGAAAAGGCTGGCTGAAAAC-3', } \\
\text { R: 5'-TCGATAACTCCTGAACCACTG-3', }\end{array}$ & 60 & 40 & 468 \\
\hline CXCL10 & $\begin{array}{l}\text { F: 5'- ACCTCCAGTCTCAGCACCATG -3' } \\
\text { R: 5'- TGGGAGGATGGCAGTGGAAG -3' }\end{array}$ & 60 & 40 & 761 \\
\hline IFN- $\beta$ & $\begin{array}{l}\text { F: 5'- CCTGTGGCAATTGAATGGGAGGC -3' } \\
\text { R: 5'- CCAGGCACAGTGACTGTACTCCTT -3' }\end{array}$ & 57 & 40 & 370 \\
\hline GAPDH & $\begin{array}{l}\text { F: 5'- GCACCGTCAAGGCTGAGAAC -3' } \\
\text { R: 5'- ATGGTGGTGAAGACGCCAGT -3' }\end{array}$ & 55 & 40 & 142 \\
\hline
\end{tabular}


al. 2011). Briefly, the cells (about $5 \times 10^{5}$ ) were lysed with $50 \mu 1$ of Laemmli's reducing sample buffer. The lysate was subjected to electrophoresis on a $7.5 \%$ or $10 \%$ polyacrylamide gel and proteins were transferred to a polyvinylidene difluoride membrane. The membrane was blocked with TBS $+0.1 \%$ Tween $20+1 \%$ non-fat dry milk, and incubated with an antibody against MDA5 (1:100 dilution), TLR3 (1:2,500 dilution), RIG-I (1:10,000 dilution) or actin (1:1,000 dilution), and subsequently with horseradish peroxidase-labeled anti-rabbit IgG. Immunodetection was performed using a chemiluminescence substrate.

\section{ELISA for CXCL10 and IFN- $\beta$}

The concentrations of CXCL10 and IFN- $\beta$, in cell-conditioned medium, were measured using sandwich ELISA kits.

\section{Immunofluorescent staining for MDA5}

In the present study, stored kidney specimens in good condition obtained from 6 cases were used for immunefluorescent study of the MDA5 and RIG-I expressions. The patients include 2 cases of International Society of Nephrology/Renal Pathology Society (ISN/ RPS) class IV-G lupus nephritis with activity index, 14 and 8; chro- nicity index, 7 and 2, respectively, according to the histologic scores described by Austin et al (1984), 2 cases of proteinuric (the urinary protein/creatinine ratio over 1.0) IgA nephropathy with activity index, 4 and 3; chronicity index, 4 and 3, respectively, according to the histologic scores described by Andreoli and Bergnistein (1989), a case of minimal change nephrotic syndrome (MCNS) and a case of nutcracker syndrome. In these patients, renal biopsy specimens were obtained as a routine diagnostic clinical examination before the study, and were subsequently stored. Informed consent was obtained from all study participants. The specimens were cut using a cryostat, and the sections were fixed briefly in cold acetone and air-dried. The slides were washed in phosphate-buffered saline immediately before the immunohistochemical procedure. After blocking by incubation with $1 \%$ goat serum, the slides were incubated with an anti-MDA5 antibody (1:100) or an anti-RIG-I antibody $(1: 1,000)$. Then the samples were incubated with an FITC-conjugated secondary anti-rabbit IgG antibody (1:40). The microscopy was Olympus IX70 model, and the magnification used was x200. The study was approved by the Committee of Medical Ethics of Hirosaki University Graduate School of Medicine.

\section{A. real-time PCR}

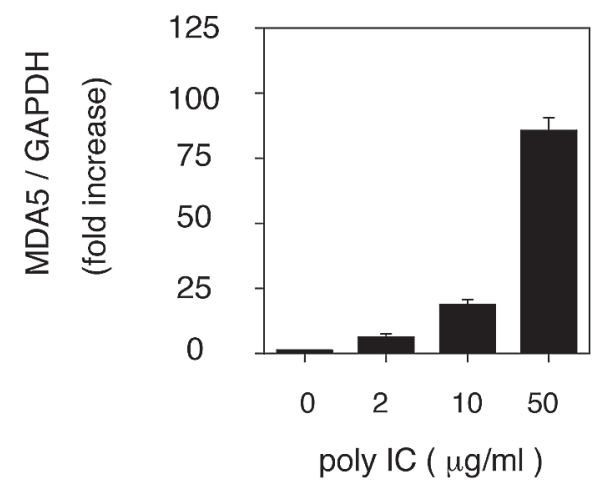

B. western blot

\section{C. real-time PCR}

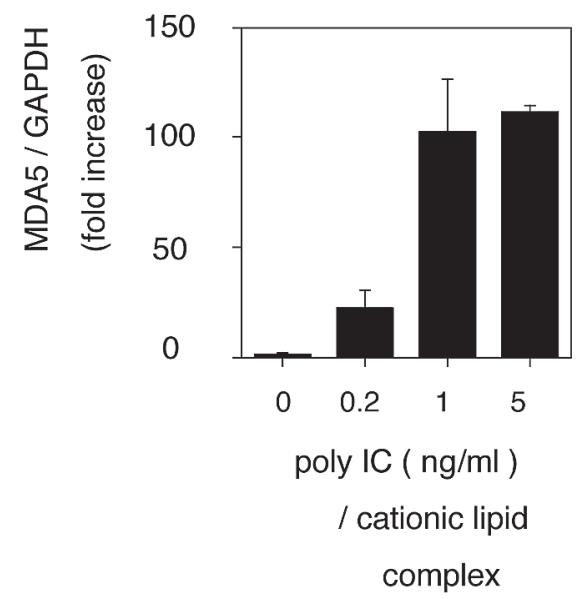

\section{D. western blot}

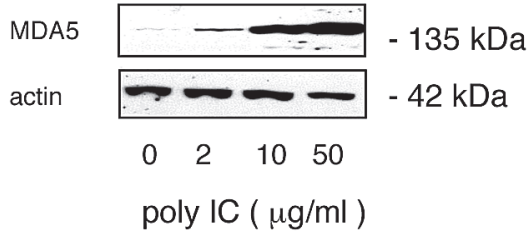

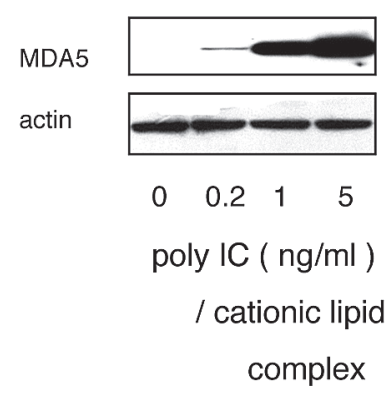

Fig. 1. Poly IC induces the expression of MDA5 in normal human mesangial cells in concentration-dependent manners. (A) Mesangial cells were simply treated with various concentrations of poly IC for $16 \mathrm{~h}$. Total RNA was extracted from the cells and the expression of MDA5 mRNA was examined by real-time RT-PCR analysis. (B) The cells were treated with poly IC as in (A), and lysed after $24 \mathrm{~h}$ incubation. The expression of MDA5 protein was examined by western blot analysis. (C) The cells were transfected with various concentrations of poly IC complexed with a cationic lipid, lipofectamine RNAiMAX (poly IC / cationic lipid). After $16 \mathrm{~h}$ incubation, the expression of MDA5 mRNA was analyzed by real-time RT-PCR. (D) The cells were transfected with poly IC / cationic lipid as in (C), and were incubated for $24 \mathrm{~h}$. The cell lysates were subjected to western blot as in (B). 
Statistics

Values are expressed as mean \pm S.D. $(n=3)$, and statistical significance was analyzed by Student's or Welch's $t$-test.

\section{Results}

Poly IC induces MDA5 in human mesangial cells

Only a small amount of MDA5 mRNA and protein was detected in mesangial cells under resting condition; and poly IC, either simply applied to the cells or transfected as a complex with a cationic lipid, induced MDA5 expression in a concentration-dependent manner (Fig. 1A-D). Poly IC treatment induced MDA5 expression at the concentration of $2-50 \mu \mathrm{g} / \mathrm{ml}$, and a similar level of expression was observed in the cells transfected with $0.2-5 \mathrm{ng} / \mathrm{ml}$ of poly IC complexed with a cationic lipid.

Poly IC induced MDA5 in a time-dependent manner. Poly IC treatment of the cells rapidly induced MDA5
mRNA and significant increase in the mRNA level was observed $4 \mathrm{~h}$ after poly IC treatment (Fig. 2A), while MDA5 mRNA started to increase $8 \mathrm{~h}$ after the transfection with poly IC/cationic lipid complex (Fig. 2B). MDA5 mRNA reached a maximal level after about $16 \mathrm{~h}$ both in the cells treated with poly IC or those transfected with a poly IC/cationic lipid complex (Fig. 2A and B). The expression of MDA5 protein reached a maximal level $16 \mathrm{~h}$ after poly IC treatment (Fig. 2C) or $48 \mathrm{~h}$ after the transfection (Fig. 2D).

Involvement of TLR3 or RIG-I in poly IC-induced MDA5 induction

Transfection of the cells with siRNA against TLR3 suppressed the poly IC-induced expression of MDA5 mRNA (Fig. 3A) and protein (Fig. 3B); however, such an effect was observed only in the cells treated with poly IC

\section{A. real-time PCR}

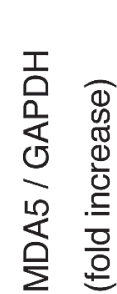

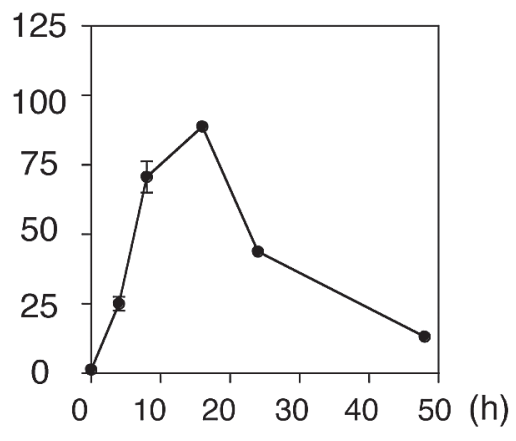

poly IC

\section{C. western blot}

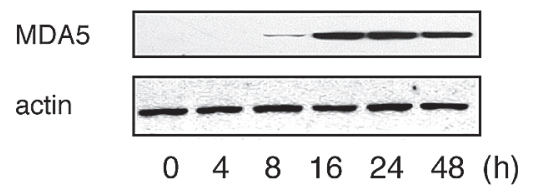

poly IC

\section{B. real-time PCR}

\section{D. western blot}

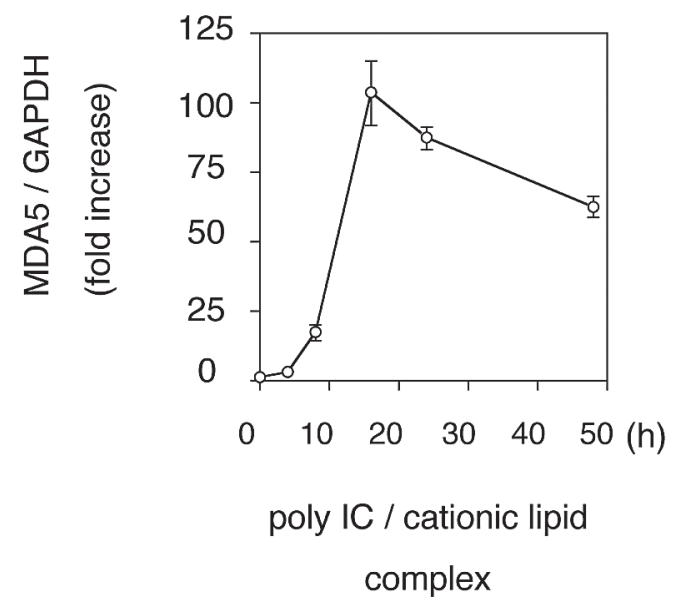

Fig. 2. Poly IC induces the expression of MDA5 in time-dependent manners. (A) The cells were treated with $30 \mu \mathrm{g} / \mathrm{ml} \mathrm{poly}$ IC for up to $48 \mathrm{~h}$, and the expression of MDA5 mRNA was analyzed by real-time RT-PCR. (B) The cells were transfected with $1 \mathrm{ng} / \mathrm{ml}$ poly IC / cationic lipid, and incubated for up to $48 \mathrm{~h}$. Real-time RT-PCR was performed as in (A). (C) The cells were treated with poly IC as in (A) and the cells were lysed. The lysates were subjected to western blot analysis for MDA5. (D) The cells were transfected with poly IC / cationic lipid as in (B), and western blot was performed. 
A. real-time PCR

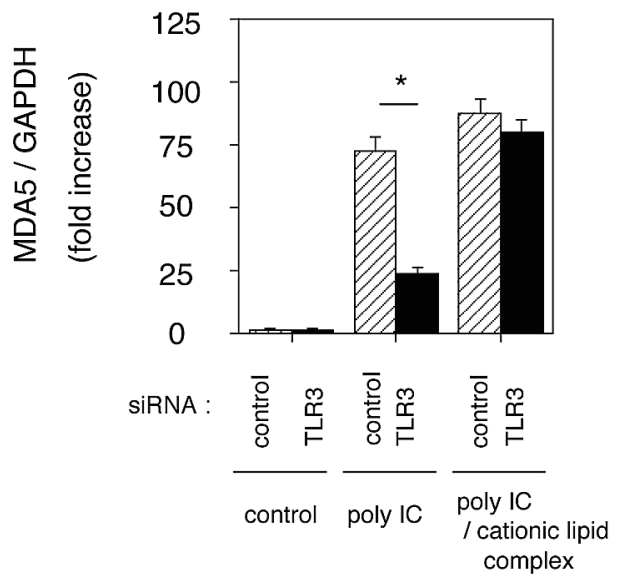

B. western blot

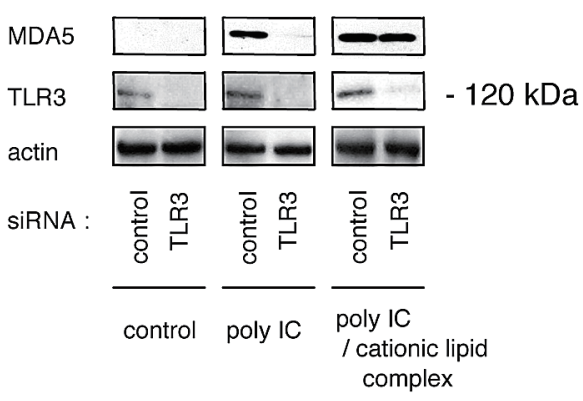

C. real-time PCR

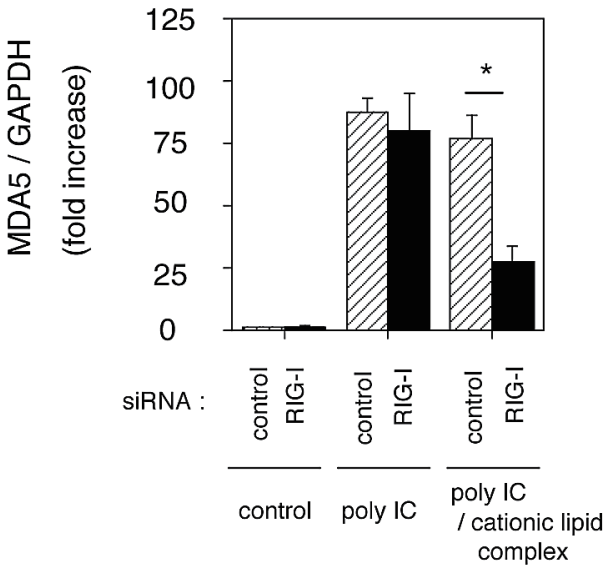

D. western blot

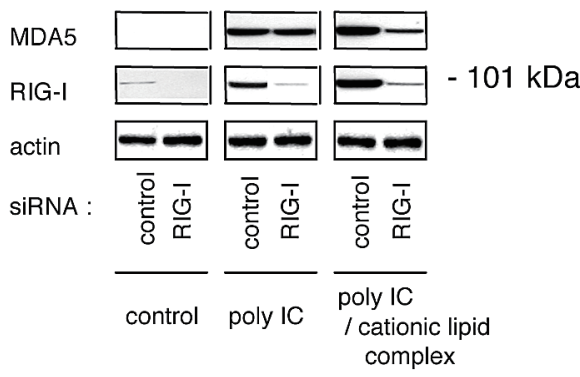

E. western blot

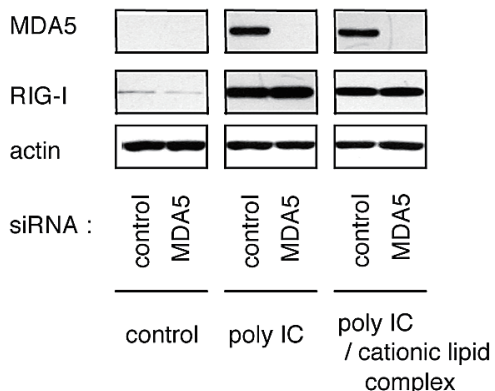

Fig. 3. TLR3 or RIG-I is involved in MDA5 induction by treatment with poly IC or by transfection with poly IC / cationic lipid, respectively. Mesangial cells were transfected with siRNA against TLR3, RIG-I, MDA5 or a non-silencing control siRNA. Twenty-four hours after transfection, the cells were treated with $30 \mu \mathrm{g} / \mathrm{ml}$ poly IC or were transfected with the complex of $1 \mathrm{ng} / \mathrm{ml}$ poly IC / cationic lipid. After $16 \mathrm{~h}$ or $24 \mathrm{~h}$ incubation, the cells were subjected to real-time RT-PCR (A, C) or western blot (B, D and E) analysis, respectively $\left({ }^{*} p<0.01, n=3\right)$.

and the MDA5 induction elicited by a poly IC/cationic lipid complex (Fig. 3A and B) was not affected. RNA interference against RIG-I markedly inhibited only the MDA5 expression induced by a poly IC/cationic lipid complex (Fig. 3C and D). Knockdown of MDA5 had no effects on the expression of RIG-I induced by poly IC or a poly IC/ cationic lipid complex (Fig. 3E).

Newly synthesized IFN- $\beta$ mediates poly IC-induced MDA5 expression

Induction of IFN- $\beta$ mRNA was observed in the cells treated with poly IC or those transfected with a poly IC/cat- ionic lipid complex. TLR3 knockdown suppressed IFN- $\beta$ induction in the poly IC-treated cells, while RIG-I knockdown suppressed the induction in the cells transfected with poly IC/cationic lipid (Fig. 4A). Transfection of the cells with IFN- $\beta$ siRNA markedly inhibited production of MDA5 and CXCL10 induced by poly IC treatment or poly IC/cationic lipid transfection (Fig. 4B and C). It was confirmed by an ELISA that knockdown of IFN- $\beta$ was effective (Fig. $4 \mathrm{D})$. On the other hand, MDA5 was induced by the transfection with an IFN- $\beta$ expression plasmid (Fig. 4E and F). The result of an ELISA confirmed the overexpression of IFN- $\beta$ (Fig. 4G). Treatment of cells with $\mathrm{r}(\mathrm{h}) \mathrm{IFN}-\beta$ also 


\section{A. real-time PCR}

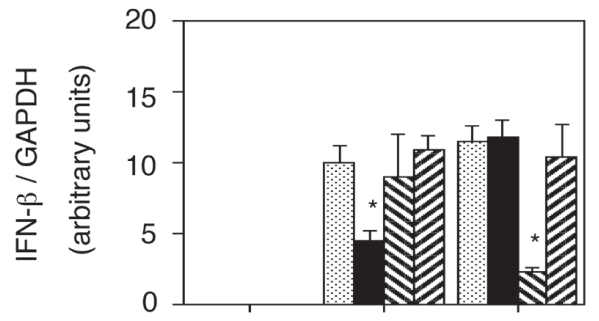

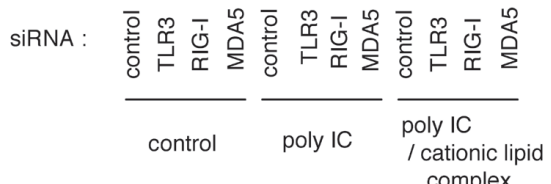

\section{ELISA}

B. real-time $\mathrm{PCR}$
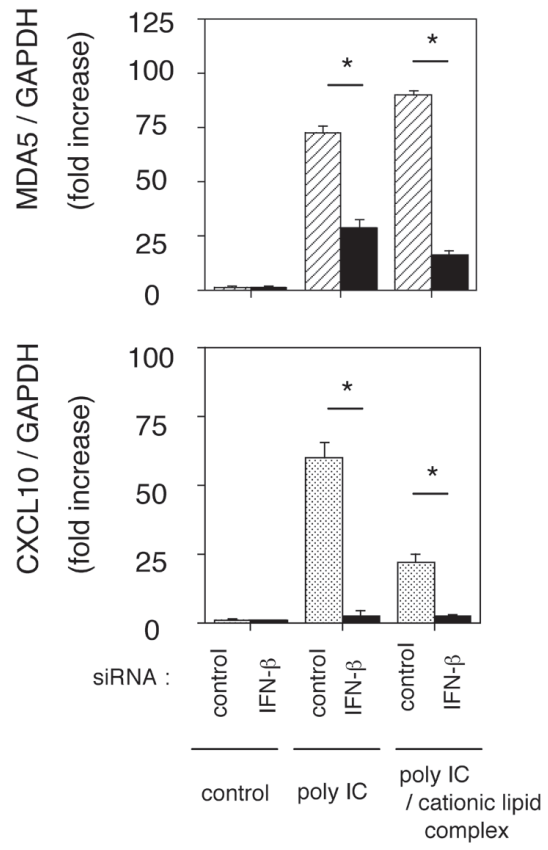

C. western blot

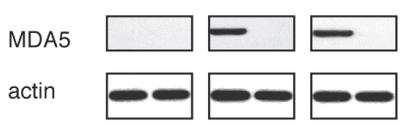

SiRNA :

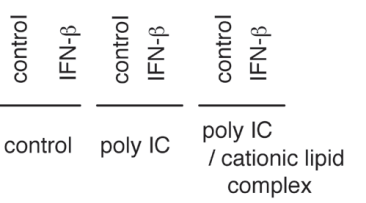

F. western blot

MDA5

actin

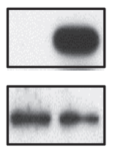

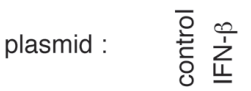

G. ELISA

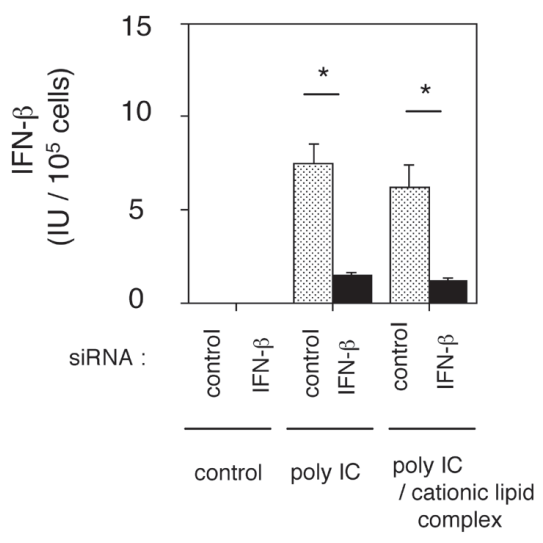

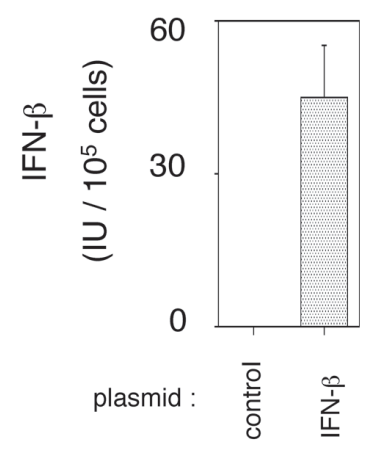

E. real-time PCR

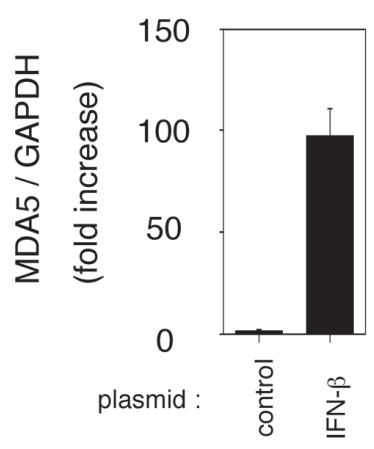

H. real-time PCR

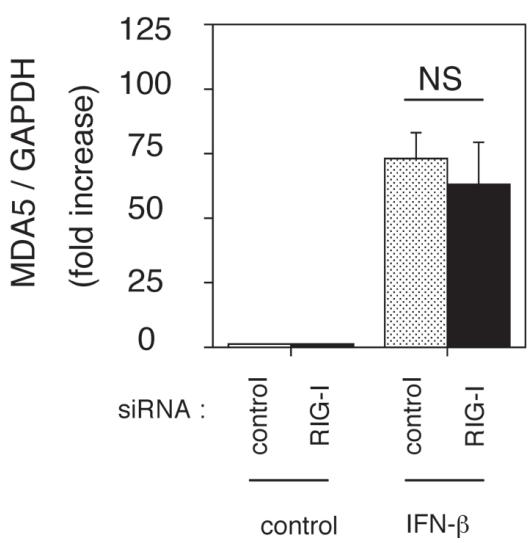

Fig. 4. Newly synthesized IFN- $\beta$ is involved in the induction of MDA5 by poly IC. (A) The mesangial cells were transfected with a non-silencing control siRNA, siRNA against TLR3, RIG-I or MDA5. After $24 \mathrm{~h}$ of transfection, the cells were treated or transfected with poly IC as in Fig. 3. RNA was extracted from cells after additional $4 \mathrm{~h}$ incubation, and the expression of IFN- $\beta$ mRNA was examined using real-time PCR analysis ( ${ }^{*} p<0.01$ vs. control, $n=3$ ). (B, C, D) The cells were transfected with siRNA against IFN- $\beta$, and subsequently treated with poly IC or transfected with poly IC / cationic lipid complex. RNA was extracted after additional $16 \mathrm{~h}$ incubation, and real-time PCR analysis for MDA5 or CXCL10 was performed $\left({ }^{*} p<0.01, n=3\right.$ ) (B). The cells were lysed after additional $24 \mathrm{~h}$ incubation, and the lysates were subjected to western blot analysis for MDA5 (C). The conditioned medium was collected, and the concentration of IFN- $\beta$ was measured using an ELISA $(* p<0.01, n=3)(\mathrm{D})$. (E, F, G) The cells were transfected with an expression plasmid for IFN- $\beta$ and incubated for $24 \mathrm{~h}$. Real-time PCR (E) and western blot (F) for MDA5, and ELISA for IFN- $\beta$ (G) were performed. (H) The cells were transfected with siRNA against RIG-I. After $24 \mathrm{~h}$ incubation, the cells were treated with $10 \mathrm{ng} / \mathrm{ml} \mathrm{r}(\mathrm{h})$ IFN- $\beta$ for $8 \mathrm{~h}$. RNA was extracted from the cells and real-time PCR analysis for MDA5 was performed. 
A. real-time PCR

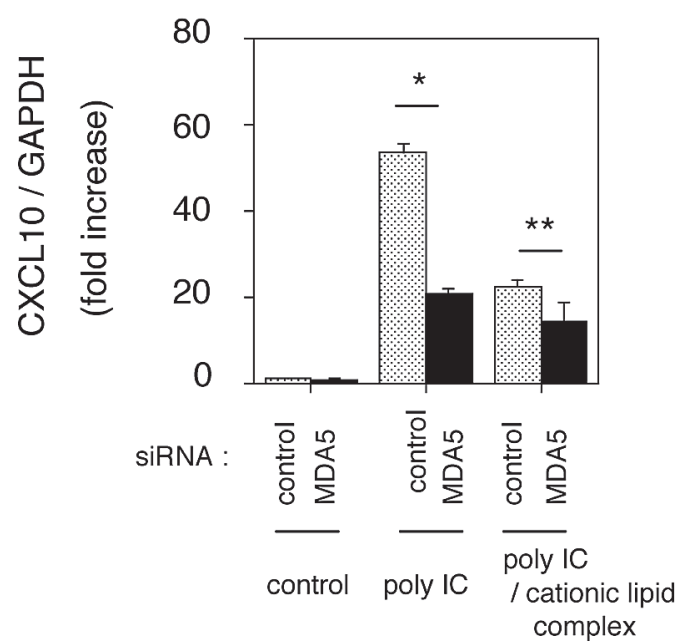

B. ELISA

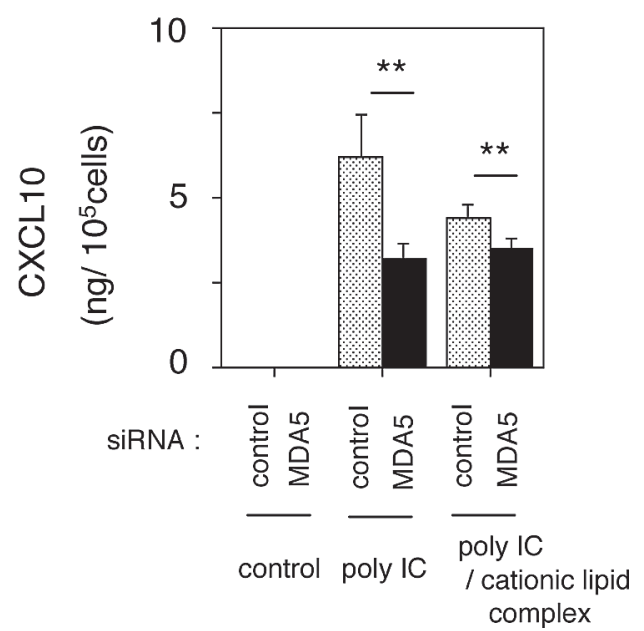

Fig. 5. Knockdown of MDA5 decreases the induction of CXCL10 by treatment with poly IC or by transfection with poly IC / cationic lipid. The cells were transfected with siRNA against MDA5. Twenty-four hours after transfection, the cells were treated or transfected with poly IC as in Fig. 3. After additional $24 \mathrm{~h}$ incubation, the conditioned medium was collected and RNA was extracted from the cells. Real-time RT-PCR (A) or ELISA (B) for CXCL10 was performed $(* p<$ 0.01 and $* * p<0.05, n=3)$.

induced MDA5 mRNA, and RNA interference against RIG-I did not affect the induction (Fig. 4H).

\section{MDA5 is involved in CXCL10 induction by poly IC}

Expression of CXCL10 in resting cells was faint and poly IC treatment or transfection markedly enhanced the expression. Knockdown of MDA5 resulted in partial inhibition of CXCL10 induction by poly IC or poly IC/cationic lipid complex (Fig. 5A and B).

Enhanced expression of MDA5 in kidney tissues from patients with proliferative lupus nephritis or proteinuric IgA nephropathy

The results of immunofluorescent staining are shown in Fig. 6. Intense MDA5 immunoreactivity was detected in mesangial cells of renal biopsy specimens obtained from patients with severe lupus nephritis nephritis with IV-G (A/ C) according to the classification of ISN/RPS system (Fig. 6A) or proteinuric IgA nephropathy (Fig. 6C), while the expression in non-immune complex-mediated diseases, nutcracker syndrome (Fig. 6E) or MCNS (not shown) was undetectable. Parallel immunohistochemical analyses revealed glomerular RIG-I expression only in severe lupus nephritis with IV-G (A/C) (Fig. 6B).

\section{Discussion}

It has been shown that MDA5 is induced by poly IC treatment or viral infection in various types of cells, including human bronchial epithelial cells (Wang et al. 2009), primary human pancreatic islets (Skog et al. 2011) and human conjunctival epithelial cells (Ueta et al. 2010); however, little is known about the mechanisms by which the MDA5 expression is regulated. In the present study, we demonstrated MDA5 induction in normal human mesangial cells in response to the treatment with poly IC or to the transfection with poly IC/cationic lipid complex. MDA5 induction was observed more rapidly in the cells simply treated with poly IC than those transfected with poly IC/cationic lipid complex. This result suggests that poly IC and a poly IC/ cationic lipid complex induce MDA5 via a signaling pathway different from each other. Along with TLR3 and RIGI, MDA5 is known as a recognition receptor for dsRNA. TLR3 is localized in the endosomes, whereas RIG-I and MDA5 are in the cytoplasm. Knockdown of TLR3 inhibited the MDA5 induction by poly IC treatment, while RIG-I knockdown suppressed the MDA5 induction by a poly IC/ cationic lipid complex. Thus, TLR3 may serve as a receptor for non-transfected poly IC and RIG-I as a receptor for transfected poly IC. Knockdown of MDA5 had no effect on the RIG-I induction by poly IC/cationic lipid complex. This suggests that MDA5 may not work as a receptor for poly IC and may be located in the downstream of RIG-I in this signaling pathway. These results are inconsistent with a previous report which showed that MDA5, but not RIG-I, was required for signaling induced by poly IC/cationic lipid complex in mouse mesangial cells (Flur et al. 2009). The pathogen recognition and downstream signaling pathway may be differentially regulated between human and mouse.

IFN- $\beta$ has anti-viral and anti-tumor properties and is involved in the pathogenesis of autoimmune diseases such as lupus nephritis (Nacionales et al. 2007). Viral RNA and DNA can activate IFN signaling in glomerular mesangial cells and endothelial cells. IFN signaling is necessary in antiviral responses in glomeruli, and IFN- $\beta$ is regarded as 


\section{MDA5}
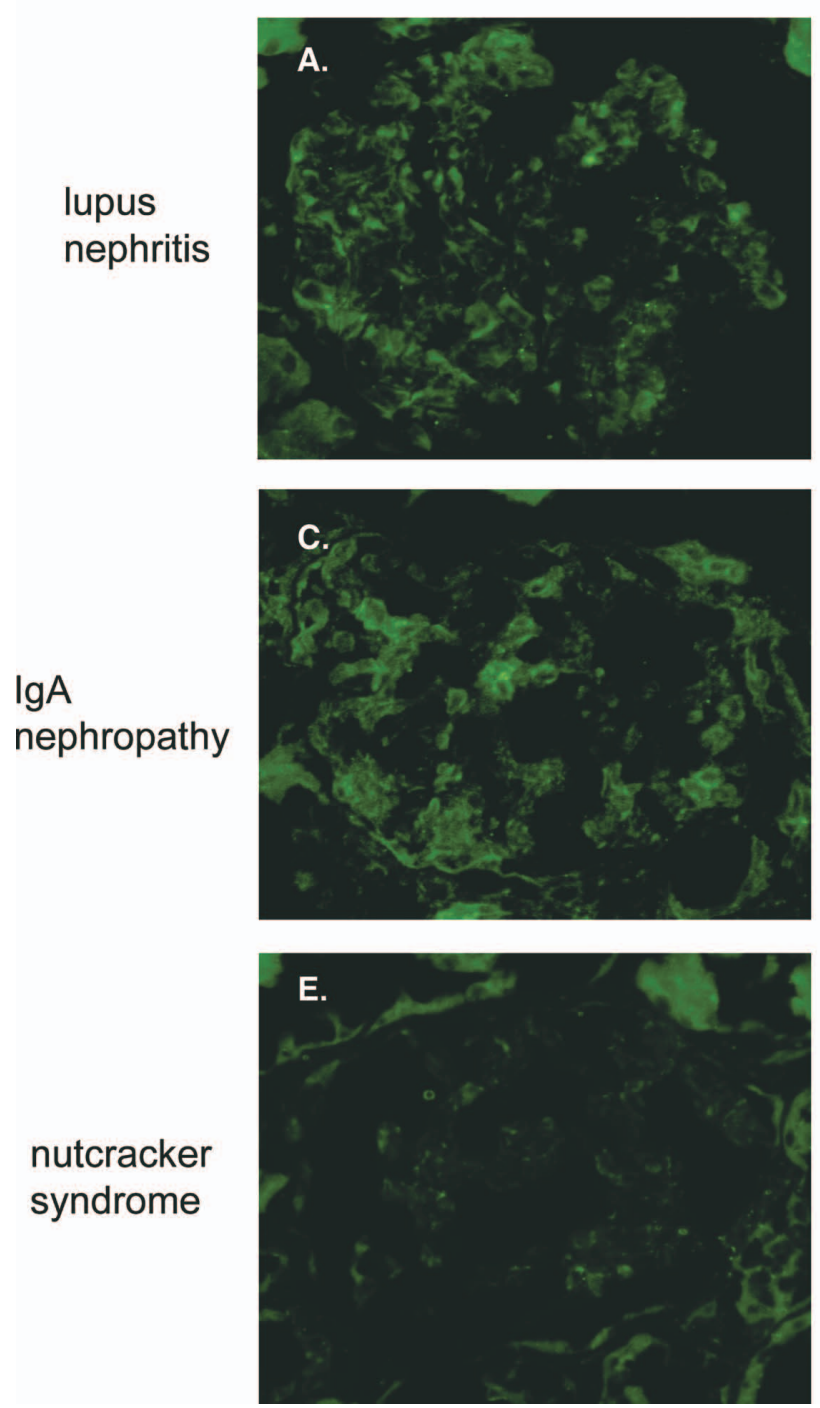
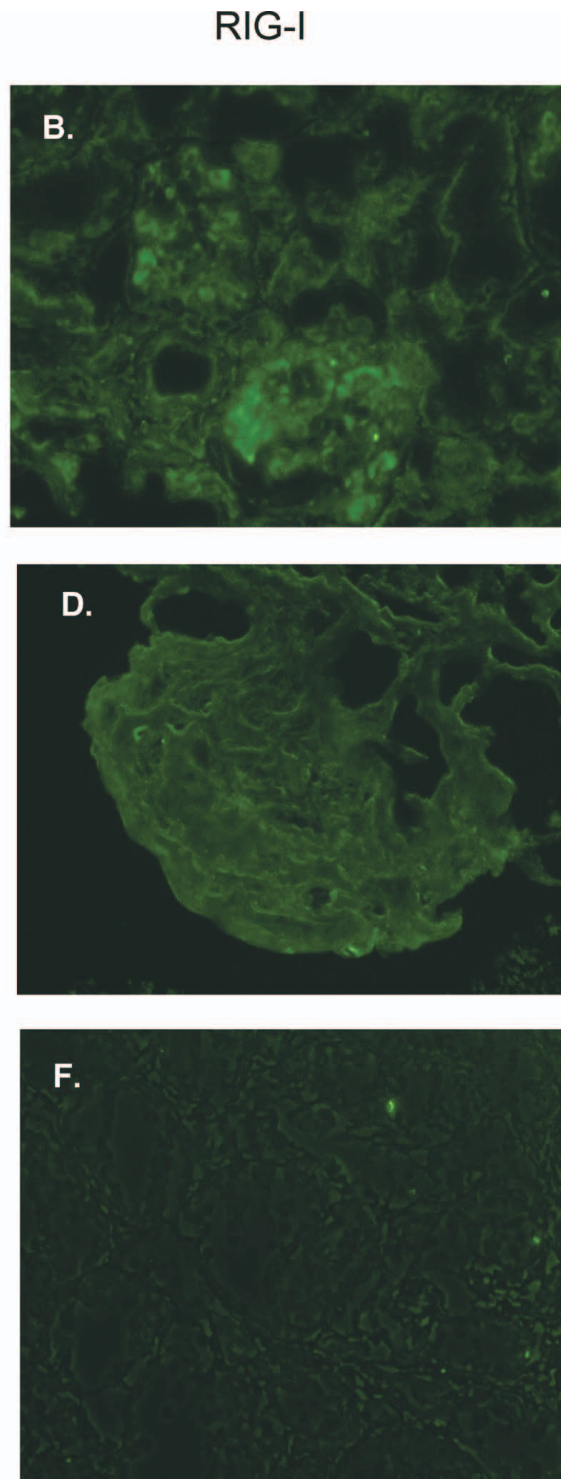

Fig. 6. Immunofluorescent staining for MDA5 and RIG-I in renal biopsy specimens. Renal biopsy specimens obtained from patients with severe lupus nephritis with ISN/RPS IV-G (A/C) (A and B), proteinuric IgA nephropathy (C and D) or nutcracker syndrome, used as controls (E and F) were subjected to immunofluorescence staining for MDA5 (A, C and E) and RIG-I (B, D and F). Intense MDA5 immunoreactivity was detected in mesangial area of lupus nephritis (A) and IgA nephropathy (C) but not in nutcracker syndrom (E) while significant increase in the immunostaining intensity for RIG-I was observed only in lupus nephritis (B). There was no immunostaining intensity for MDA5 or RIG-I in biopsy specimens obtained from patients from minimal change nephrotic syndrome (not shown). The images for lupus nephritis or IgA nephropathy are representative of two cases with similar results.

an important mediator in various viral nephropathies and in immune complex glomerulonephritis triggered by viral infections (Anders et al. 2010). IFN- $\beta$ exerts its biological properties by inducing various genes, and MDA5 was originally identified as an IFN- $\beta$-inducible gene (Kang et al. 2002). In our previous studies, poly IC treatment of mesangial cells induced the expression of IFN- $\beta$ and de novo synthesized IFN- $\beta$ mediated the expression of RIG-I (Imaizumi et al. 2010) and ISG20 (Imaizumi et al. 2011). In the present study, we confirmed that IFN- $\beta$ is induced either by poly IC or a poly IC/cationic lipid complex. Moreover, the expression of IFN- $\beta$, as well as MDA5, was inhibited by
TLR3 knockdown in poly IC-treated cells or by RIG-I knockdown in poly IC-transfected cells. RNA interference against IFN- $\beta$ suppressed the MDA5 induction either by poly IC or by poly IC/cationic lipid complex, and overexpression of IFN- $\beta$ resulted in MDA5 induction. These results suggest that de novo synthesized IFN- $\beta$ may mediate the expression of MDA5 induced either by poly IC or by poly IC/cationic lipid complex. We also examined if RIG-I is involved in the IFN- $\beta$-induced MDA5 expression and RIG-I knockdown had no effect on the IFN- $\beta$-induced expression of MDA5. RIG-I, as a cytoplasmic poly IC receptor, is involved in IFN- $\beta$ expression induced by poly 


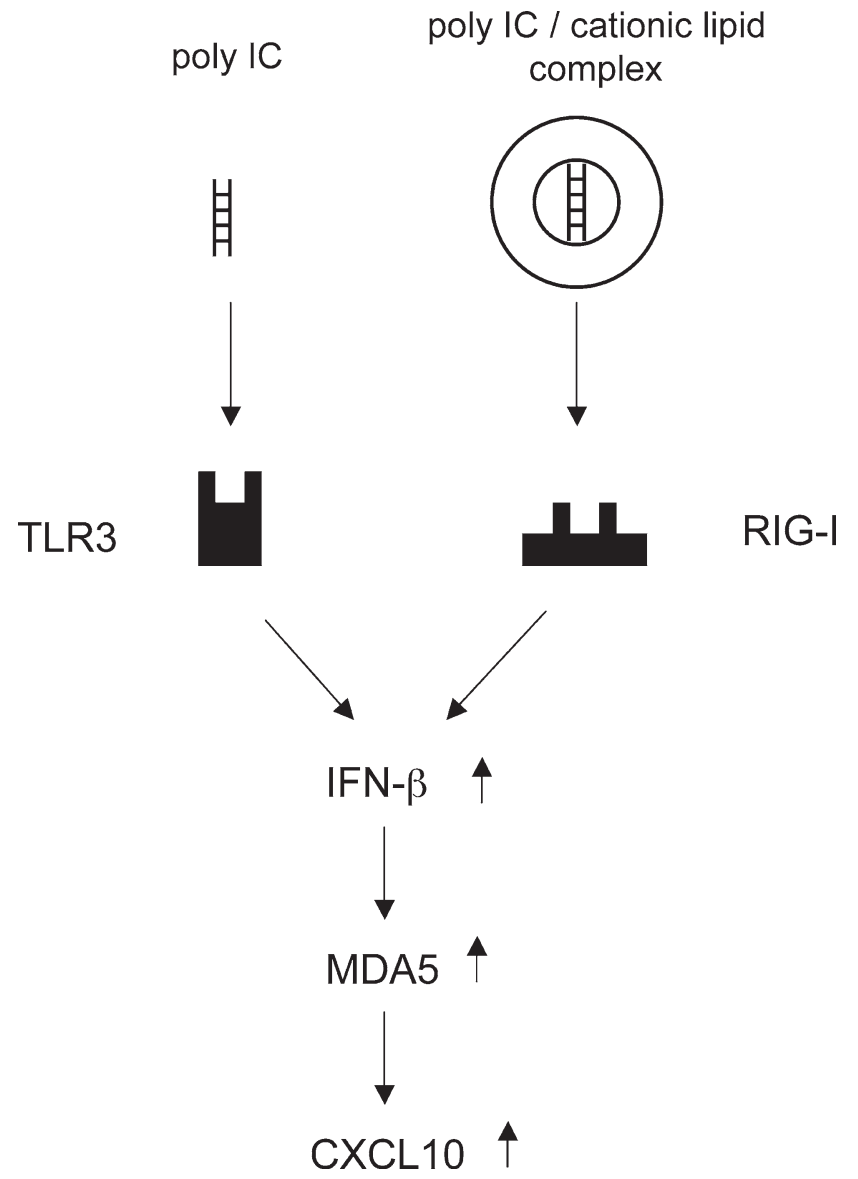

Fig. 7. Proposed TLR3/IFN- $\beta /$ MDA5/CXCL10 and RIG-I/ IFN- $\beta /$ MDA5/CXCL10 signaling pathways in response to treatment with poly IC or to transfection with poly IC / cationic lipid in human mesangial cells.

IC/cationic lipid complex but not in the MDA5 expression induced by IFN- $\beta$.

CXCL10 is a chemokine with chemotactic activity toward the leukocytes that express its receptor CXCR3. CXCL10 is implicated in the pathogenesis of glomerular nephritis including lupus nephritis (Das and Brunner 2009; Reyer-Thomas et al. 2011) and IgA nephropathy (Duque et al. 1997). MDA5 is known to mediate CXCL10 induction in human bronchial epithelial cells infected with Rhinovirus (Wang et al. 2009). In the present study, CXCL10 expression induced by poly IC or poly IC/cationic lipid was partially, but significantly, inhibited in response to MDA5 knockdown. However, the inhibition of CXCL10 expression by MDA5 knockdown was partial, suggesting that other MDA5-independnt pathway(s) also mediates poly IC-induced CXCL10 expression. Thus MDA5 may be involved, at least in part, in the poly IC-mediated expression of CXCL10 in mesangial cells. Enhanced expression of CXCL10 in mesangial cells may result in leukocyte infiltration into the kidneys and promote renal inflammatory injury. Taken together, these results suggest the involvement of the TLR3/IFN- $\beta$ /MDA5/CXCL10 and RIG-I/ IFN- $\beta /$ MDA5/CXCL10 pathways in renal anti-viral reac- tions and inflammatory diseases (Fig. 7). A signaling molecule named virus-induced signaling adaptor (VISA)/ interferon- $\beta$-promoter stimulator (IPS-1)/mitochondrial antiviral signaling protein (MAVS) is known to be involved in MDA5 signaling (Matsumiya et al. 2011), but the role of this molecule in MDA5/CXCL10 pathway remains to be elucidated. Further studies are needed to clarify the implication of these novel pathways in mesangial inflammation and renal diseases.

Viral 5'-triphosphate RNA and double-stranded nonCpG DNA are known to be potential immunostimulatory againists for RIG-I and MDA5. It has been shown that exposure of lupus model mice to these nucleic acids aggravates glomerulonephritis by increasing IFN signaling (Allam et al. 2008). In human subjects, the expression of TLR3 (Patole et al. 2005) and RIG-I (Suzuki et al. 2007) is enhanced in mesangial area of kidney tissues from patients with severe lupus nephritis. We detected, in the present study, MDA5 immunoreactivity in renal mesangial area of the tissues from patients with severe lupus nephritis and proteinuric IgA nephropathy while no MDA5 expression in MCNS and nutcracker syndrome was observed. Interestingly, there was no glomerular expression of RIG-I in the specimen from proteinuric IgA nephropathy, despite of positive staining of MDA5. These observations suggest that the expression of MDA5 in severe lupus nephritis is associated with the activation of signaling pathway via RIG-I but MDA5 expression in IgA nephropathy is independent on RIG-I. Differential roles of MDA5 and RIG-I in severe lupus nephritis and proteinuric IgA nephropathy may predict specific molecular mechanisms for these diseases. This should be further investigated in future studies. Clinical impact of this study also remains speculative, since the immunohistolologic study was performed using stored biopsy specimen obtained from only 6 patients with or without glomerulonephritis. Thus, further studies involving a larger number of patients are needed to resolve this issue.

We conclude that poly IC induces MDA5, and MDA5 is involved in at least partly in poly IC-induced CXCL10 expression in human mesangial cells. MDA5 may play a role in anti-viral and inflammatory reactions in the glomerulus. This provides novel insights not only into the physiological host defense mechanisms against viral infections in mesangial cells but also into the molecular mechanisms of chronic inflammatory renal diseases.

\section{Acknowledgments}

This work was supported by grants-in-aid for Science from the Ministry of Education, Culture, Sports, Science and Technology of Japan (T.I. and H.T.), the Karoji Memorial Fund for Medical Research in Hirosaki University (T.I. and K.T.) and Grant for Exploratory Research by Young Scientist in Hirosaki University (K.T.). The authors thank A. Yamamoto, K. Nakata and K. Munakata for help.

\section{Conflict of Interest}

The authors have no conflict of interest to declare. 


\section{References}

Allam, R., Pawar. R.D., Kulkarni, O.P., Hornung, V., Hartmann, G., Segerer, S., Akira, S., Endres, S. \& Anders, H.J. (2008) Viral 5 '-triphosphate RNA and non-CpG DNA aggravate autoimmunity and lupus nephritis via distinct TLR-independent immune responses. Eur. J. Immunol., 38, 3487-3498.

Allam, R., Lichtnekert, J., Moll, A.G., Taubitz, A., Vielhauer, V. \& Anders, H.J. (2009) Viral RNA and DNA trigger common antiviral responses in mesangial cells. J. Am. Soc. Nephrol., 20, 1986-1996.

Anders, H.J., Lichnekert, J. \& Allam, R. (2010) Interferon- $\alpha$ and $-\beta$ in kidney inflammation. Kidney Int., 77, 848-854.

Andreoli, S.P. \& Bergstein, J.M. (1989) Treatment of severe IgA nephropathy in children. Pediatr. Nephrol., 3, 248-253.

Austin, H.A.3rd., Muenz L.R., Joyce, K.M., Antonnovych, T.T. \& Bakow, L.E. (1984) Diffuse proliferative lupus nephritis: identification of specific pathogenic features affecting renal outcome. Kidney Int., 25, 689-695.

Das, L. \& Brunner, H.I. (2009) Biomarkers for renal disease in childhood. Curr. Rheumatol. Rep., 11, 218-225.

Duque, N., Gomez-Guerrero, C. \& Egido, J. (1997) Interaction of IgA with Fc alpha receptors of human mesangial cells activates transcription factor nuclear factor- $\kappa \mathrm{B}$ and induced expression and synthesis of monocyte chemoattractant protein-1, IL-8, and IFN-inducible protein10. J. Immunol., 159, 3474-3482.

Flur, K., Allam, R., Zecher, D., Kulkarni, O.P., Lichtnekert, J., Schwarz, M., Buetler, B., Vielhuer, V. \& Anders, H.J. (2009) Viral RNA induces type I Interferon-dependent cytokine release and cell death in mesangial cells via melanoma-differentiation-associated gene-5. Implications for viral infectionassociated glomerulonephritis. Am. J. Pathol., 175, 20142022.

Imaizumi, T., Aratani, S., Nakajima, T., Carlson, M., Matsumiya, T., Tanji, K., Ookawa, K., Yoshida, H., Tsuchida, S., McIntyre, T.M., Prescott, S.M., Zimmerman, G.A. \& Satoh, K. (2002) Retinoic acid-inducible gene-I (RIG-I) is induced in endothelial cells by LPS and regulates expression of COX-2. Biochem. Biophys. Res. Commun., 292, 274-279.

Imaizumi, T., Tanaka, H., Matsumiya, T., Yoshida, H., Tanji, K., Tsuruga, K., Oki, E., Yashiro, T., Ito, E. \& Satoh, K. (2010) Retinoic acid-inducible gene-I is induced by double-stranded RNA and regulates the expression of CCL5 in human mesangial cells. Nephrol. Dial. Transplant., 25, 3534-3539.

Imaizumi, T., Tanaka, H., Mechti, N., Matsumiya, T., Yoshida, H., Sato, F., Aizawa-Yashiro, T., Tsuruga, K., Hayakari, R. \& Satoh, K. (2011) Polyinosinic-polycytidylic acid induces the expression of interferon-stimulated gene 20 in mesangial cells. Nephron. Exp. Nephrol., 119, e40-48.

Jiang, L.J., Zhang, N.N., Ding, F., Li, X.Y., Chen, L., Zhang, H.X., Zhang, W., Chen, S.J., Wang, Z.G., Li, J.M., Chen, Z. \& Zhu,
J. (2011) RA-inducible gene-I induction augments STAT1 activation to inhibit leukemia cell proliferation. Proc. Natl. Acad. Sci. USA, 108, 1897-1902.

Kang, D.C., Gopalkrishnan, R.V., Wu, Q., Jankowsky, E., Pyle, A.M. \& Fisher, P.B. (2002) Mda-5: an interferon-inducible putative RNA helicase with double-stranded RNA-dependent ATPase activity and melanoma growth-suppressive properties. Proc. Natl. Acad. Sci. USA, 99, 637-642.

Lai, A.S. \& Lai, K.N. (2006) Viral nephropathy. Nat. Clin. Pract. Nephrol., 2, 254-262.

Matsumiya, T., Imaizumi, T., Yoshida, H. \& Satoh, K. (2011) Antiviral signaling through retinoic acid-inducible gene-I-like receptors. Arch. Immunol. Ther. Exp., 59, 41-48.

Nacionales, D.C., Kelly-Scumpia, K.M., Lee, P.Y., Weinstein, J.S., Lyons, R., Sobel, E., Satoh, M. \& Reeves, W.H. (2007) Deficiency of the type I interferon receptor protects mice from experimental lupus. Arthritis Rheum., 56, 3770-3783.

Patole, P.S., Grone, H.J., Segerer, S., Ciubar, R., Belemezova, E., Henger, A., Kretzler, M., Shlondolff, D. \& Anders, H.J. (2005) Viral double-stranded RNA aggravates lupus nephritis through Toll-like receptor 3 on glomerular mesangial cells and antigenpresenting cells. J. Am. Soc. Nephrol., 16, 1326-1338.

Reyer-Thomas, J., Blanco, I. \& Putterman, C. (2011) Urinary biomarkers in lupus nephritis. Clin. Rev. Allergy Immunol., 40, 138-150.

Schwer, B. (2001) A new twist on RNA helicases: DExH/D box proteins as RNPases. Nat. Struct. Biol., 8, 113-116.

Skog, O., Korsgren, O. \& Frisk, G. (2011) Moduration of innate immunity in human pancreatic islets infected with enterovirus in vitro. J. Med. Virol., 83, 658-664.

Suzuki, K., Imaizumi,T., Tsugawa, K., Ito, E. \& Tanaka, H. (2007) Expression of retinoic acid-inducible gene-I in lupus nephritis. Nephrol. Dial. Transplant., 22, 2407-2409.

Ueta, M., Mizushima, K., Yokoi, N., Naito, Y. \& Kinoshita, S. (2010) Gene-expression analysis of polyI : C-stimulated primary human conjunctival epithelial cells. Br. J. Ophthalmol., 94, 1528-1532.

Wang, Q., Nagarkar, D.R., Bowman, E.R., Schneider, D., Gosangi, B., Lei, J., Zhao, Y., McHenry, C.L., Burgens, R.V., Miller, D.J., Sajjan, U. \& Hershenson, M.B. (2009) Role of doublestranded RNA pattern recognition receptors in Rhinovirusinduced airway epithelial cell responses. J. Immunol., 183, 6989-6997.

Wörnle, M., Roeder, M., Sauter, M. \& Ribeiro, A. (2009) Role of matrix metalloproteinases in viral-associated glomerulonephritis. Nephrol. Dial. Transplant., 24, 1113-1121.

Yoneyama, M., Kikuchi, M., Matsumoto, K., Imaizumi, T., Miyagishi, M., Taira, K., Foy, E., Loo, Y.N., Gale, M., Akira, S., Yonehara, S., Kato, A. \& Fujita, T. (2005) Shared and unique functions of the DExD/H-box helicases RIG-I, MDA5, and LGP2 in antiviral innate immunity. J. Immunol., 175, 2851-2858. 